\section{A Tribute to}

\section{Geoffrey Bond on}

\section{his 80th Birthday}

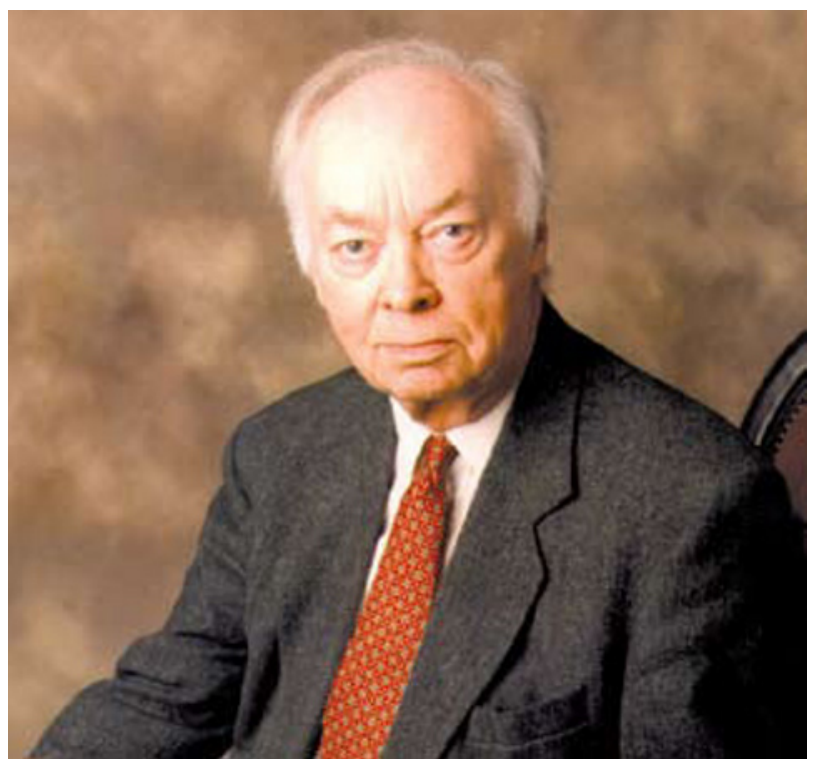

Professor Geoffrey Bond, Brunel University, UK

\section{Professor Geoffrey Bond, Brunel University, UK}

It is appropriate on the occasion of Geoffrey Bond's 80th birthday on the 21st April 2007 to review his contributions to catalysis throughout his distinguished career and, in particular, his significant contributions in recent years to assisting the rapid advance of the new area of catalysis: catalysis by gold.

Prof Bond's university education started at Birmingham University, UK where he obtained his PhD in 1951. He then carried out research as a Postdoctoral Fellow at Princeton University, USA (1951-53) and the University of Leeds, UK (1953-55) before being appointed as Lecturer and then Senior Lecturer at the University of Hull (1955-62). He then joined industry as Head of the Catalysis R\&D Laboratory, Johnson Matthey plc at Wembley in London (1962-70), before being appointed as Professor of Applied Chemistry at Brunel University in London (1970-92) where he is now Emeritus Professor. His principal areas of interest are heterogeneous catalysis by metals and oxides and he has 200 publications including patents, research papers, review articles and books. He has acted as a consultant to industry and has been President of the EUROCAT Research Group.

Geoff's activities in the 1970s included the evaluation of both gold and gold alloy catalysts (1-3), with two of his very early publications on gold catalysis being in Gold Bulletin in 1972. Supported gold on its own was found to be a very selective hydrogenation catalyst (4-6). There is a very significant paper on catalysis by gold itself published in 1973 (4):

After description of the hydrogenation of buta-1,3-diene and of but-2-yne over 1\%Au/boehmite between 400 and

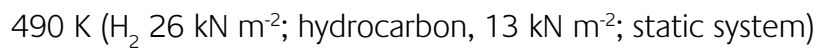
the products were found to be solely n-butene isomers. The paper then says: "We are at a loss to understand why these catalytic properties of gold have not been reported before, especially since the preparative methods we have used are in no way remarkable. We are sure that the observed activity is due solely to gold, since spectrographic analysis of the $\mathrm{HAuCl}_{4}$ by its supplier failed to detect impurities other than $\mathrm{Si}$ (3 ppm) and $\mathrm{Fe}$, Cu and $\mathrm{Ag}$ (totalling 1 ppm). We believe that making the gold particles at $380-400 \mathrm{~K}$ either introduces a large number of defects which are active sites for hydrogen dissociation, or alternatively that activity resides in some very small particles not sensed by electron microscopy."

This statement can be contrasted with the opening statement made in Geoff's first Gold Bulletin paper (1), i.e. "Although the catalytic properties of gold are surpassed by those of the Group VIII metals, especially palladium and platinum, possible applications of gold in catalytic processes have been widely studied, more especially for oxidative dehydrogenation." This undoubtedly represented the general opinion amongst catalyst investigators in the 1970s, but Geoff then goes on to say "Alloys and mixtures of gold with platinum group metals are also receiving increased attention, and the developments outlined here indicate a 
number of potential uses."

Then, following the discovery of the remarkably high catalytic activities of nanoparticulate gold for oxidation of carbon monoxide at less than room temperature and cationic gold for hydrochlorination of ethyne by Haruta and Hutchings respectively, Geoff has contributed first in helping to review what was happening in this new field of gold and gold alloy catalysis (7-9) and then producing suggestions for the theoretical basis $(10,11)$ and mechanism (9) of this new, and at the time very surprising, phenomenon. Subsequent papers have involved descriptions of experimental work and reviews (11-17). Many of these publications deal with the most important current aspects of the topic such as detailed preparative procedures $(12-14,16)$ or increasing durability $(16,18)$. Early insight into the reasons for the remarkable activity of gold catalysts was summarized in a Gold Bulletin editorial in 1998 (19) as needing careful choice of support, method of preparation (deposition- or co-precipitation), and calcination conditions, and the presence of small nanoparticles of gold.

Having written a number of well-respected books, Prof Bond's knowledge of the catalysis literature is first class, including related topics such as Faraday's 1857 work on colloidal gold. His instructive and readable books on catalysis have lead him in the last year to co-authorship of the first book on catalysis by gold (17). He is currently writing a series of papers on the experimental work done recently in collaboration with Francois Moreau at the University of Salford (e.g.18) and he is a very active member of the group of participants in the EU AURICAT project and its sequels.

Partly as a result of Geoff's valuable pioneering and continuing work on gold and gold alloy catalysts, we will soon see new commercially significant applications for gold catalysis in pollution control, chemical processing, sensor and fuel cell applications. Meanwhile, we wish Ceoff a very happy birthday, and continued good health and perceptive contributions to the exciting field of catalysis by gold.

I have very much enjoyed my stimulating collaborative work with Geoff and look forward to this continuing in the future.

\section{David Thompson}

\section{References}

1 The catalytic properties of gold, G.C. Bond, Gold Bull., 1972, 5, 11-13

2 Effect of structural disorder on the catalytic activity of gold, G.C. Bond, Gold Bull., 1972, 5, 89

3 Structure and catalytic properties of palladium-silver and palladiumgold alloys, E.G. Allison and G.C. Bond, Catal. Rev. - Sci. Eng., 1972, 7, 233-289

4 Hydrogenation over supported gold catalysts, G.C. Bond, P.A. Sermon, G. Webb, D. A. Buchanan and P. B. Wells, J. Chem. Soc. Chem. Commun., 1973, 444-445

5 Gold catalysts for olefin hydrogenation, G.C. Bond and P.A. Sermon, Gold Bull., 1973, 6, 102-105

6 Hydrogenation of alkenes over supported gold, P.A. Sermon, G.C. Bond and P.B. Wells, J. Chem. Soc. Faraday Trans., 1979, 175, 385-394

7 Catalytic hydrogenation in the liquid phase . Part 1. Hydrogenation of isoprene catalysed by palladium, palladium-gold and palladium-silver catalysts, G.C. Bond and A.F. Rawle, J. Molec. Catal. A: Chem., 1996, 109 261-271

8 Catalysis by gold, G.C. Bond and D.T. Thompson, Catal. Rev. - Sci. Eng., 1999, 41, 319-388

9 Gold-catalysed oxidation of carbon monoxide, G.C. Bond and D.T. Thompson, Gold Bull., 2000, 33, 41-51

10 Relativistic effects in coordination, chemisorption and catalysis, G.C. Bond, J. Molec. Catal. A: Chem., 2000, 156, 1-20

11 Gold: A relatively new catalyst, G.C. Bond, Gold Bull., 2001, 34, 117-119

12 The influence of metal loading and $\mathrm{pH}$ during preparation on the $\mathrm{CO}$ oxidation activity of $\mathrm{Au} / \mathrm{TiO}_{2}$ catalysts, F. Moreau, G.C. Bond and A.O. Taylor, Chem. Commun., 2004, 1642-1643

13 Gold on titania catalysts for the oxidation of carbon monoxide: control of pH during preparation with various gold contents, F. Moreau, G.C. Bond and A.O. Taylor, J. Catal., 2005, 231, 105-114

14 Gold on titania catalysts, influence of some physicochemical parameters on the activity and stability for the oxidation of carbon monoxide, F. Moreau and G.C. Bond, Appl. Catal. A: Gen., 2006, 302, 110-117

15 Status of catalysis by gold following an AURICAT Workshop, G.C. Bond and D.T. Thompson, Appl. Catal. A: Gen., 2006, 302, 1-4

16 CO oxidation activity of gold catalysts supported on various oxides and their improvement by inclusion of an iron component, $F$. Moreau and G.C. Bond, Catal. Today, 2006, 114, 362-368

17 Catalysis by gold, G.C. Bond, C. Louis and D.T. Thompson, Imperial College Press, London, 2006; http://www.icpress.co.uk/chemistry/ p450.html

18 Preservation of activity of supported gold catalysts for CO oxidation, F. Moreau and G.C. Bond, Topics Catal., 2007, in press

19 Gold: the catalytic metal for the 21st century?, G.C. Bond, Gold Bull., 1998, 31, 110 